\title{
Toonaciliatin $\mathrm{K}$ attenuates the lung injury induced by lung infection of $\mathrm{H} 1 \mathrm{~N} 1$ influenza virus by regulating the NF-אB/MyD88/TLR-7 pathway in mice
}

Xiankun Zeng, Xiaofan Zhang, Dongsheng Wei

Department of Laboratory, Tongliao City Hospital, Tongliao, Inner Mongolia Autonomous Region, China

Submitted: 30 March 2019

Accepted: 3 May 2019

Arch Med Sci 2020; 16 (6): 1387-1393

DOI: https://doi.org/10.5114/aoms.2019.86220

Copyright @ 2019 Termedia \& Banach

\section{Abstract}

Introduction: H1N1 infection has a high mortality rate due to lung injury and respiratory distress. The present study determines the protective effect of toonaciliatin $\mathrm{K}$ against the lung injury induced by the lung infection of H1N1 influenza mice and also postulates the molecular mechanism.

Material and methods: Infection was induced by exposing the anesthetized mice to H1N1 virus (10 LD50 in a volume of $30 \mu \mathrm{l}$ ) intranasally at day zero and mice were treated with toonaciliatin $\mathrm{K} 16.5$ and $33 \mathrm{mg} / \mathrm{kg}$ intragastrically for 2 weeks. The effect of toonaciliatin $\mathrm{K}$ was assessed by estimating survival rate and lung edema by the lung index. Histopathological changes were determined by $\mathrm{H}+\mathrm{E}$ staining and western blot and an RT-PCR study was also performed on the lung tissue homogenate.

Results: Data of the study suggest that toonaciliatin $\mathrm{K}$ treatment enhances the survival rate and reduces the lung index compared to infected mice. There was a decrease in the level of chemokines and cytokines in the lung tissue of the toonaciliatin $\mathrm{K}$ treated group compared to infected mice. Moreover, expression of TLR-7, NF- $\mathrm{kB}$ p65 and MyD88 protein was found to be reduced in the lung tissue of the toonaciliatin $\mathrm{K}$ treated group compared to infected mice.

Conclusions: Data of the study suggested that toonaciliatin $\mathrm{K}$ protects against lung injury in lung H1N1 lung infection by regulating the TLR-7/ Myd88/NF-KB p65 pathway.

Key words: toonaciliatin K, H1N1, infection, TLR-7, chemokine, cytokines.

\section{Introduction}

Lungs are one of the organs most exposed to the external environment and more prone for infection. Many of the bacterial pathogens including both Gram positive and Gram negative strains and viruses cause respiratory infection which causes lung injury. Influenza A (H1N1) virus induces lung infection which results in pandemic outbreaks in humans [1]. Patients suffering from acute H1N1 infection may die due to lung injury and respiratory distress. The literature reveals that enhancement of the immunity of the host improves the host defense against the viral infection [2]. In viral lung infection the levels of chemokines and inflammatory cytokines and number of immune cells are enhanced in the lung tissue [3]. In patients suffering from H1N1

\author{
Corresponding author: \\ Xiankun Zeng \\ Department \\ of Laboratory \\ Tongliao City Hospital \\ 668 Keerqin Street \\ 028000 Tongliao \\ Inner Mongolia \\ Autonomous Region \\ China \\ Phone/fax: +86 0475-8251558 \\ E-mail: EHaydukilelg@yahoo. \\ com
}


lung infection the mortality rate is high due to leukocyte and cytokine induced lung injury [4]. Toll-like receptors (TLRs) are present on immune cells which activate the expression of cytokines, phagocytosis and migration of immune cells by recognizing the pathogens [5]. TLR-7 is one the receptor of the TLR family which recognizes the single-stranded RNA (ssRNA) of the virus and which further leads to enhancement of macrophages and cytokines in the lung tissue by activating the MyD88 dependent pathway [6]. This all leads to the lung injury which could be a reason for higher mortality. In early stages of viral infection use of anti-viral drugs is avoided by physicians, which further leads to infectivity of the antiviral drug in H1N1 infection. Thus there is a need for development of an alternative medicine that could be used for the treatment of viral infection.

Toonaciliatin $\mathrm{K}$ is one of the limonoids, a secondary metabolite obtained from citrus fruits [7]. The literature reveals that limonoids possess hepatoprotective, anti-inflammatory, anti-obesity, and anticancer activity [8-11]. Toonaciliatin $\mathrm{K}$ shows anti-inflammatory properties in several models including arthritis [12]. The present investigation determines the protective effect of toonaciliatin $\mathrm{K}$ against lung injury induced by lung infection of H1N1 influenza virus.

\section{Material and methods}

\section{Animals}

Albino mice (age: 8-12 weeks; weight: 17-23 g) were used in the study. All the animals were procured from Jing Mei Company, China. Standard guidelines (humidity: $60 \pm 5 \%$; temperature: $25 \pm 2^{\circ} \mathrm{C}$ ) were used to maintain the animals with a $12 \mathrm{~h}$ light and dark cycle. Protocols of the investigation were approved by the ethics committee of Tongliao City Hospital, China (IAEC/TCH/2018/08). Influenza virus for mouse infection was provided by the Institute of Medicinal Biotechnology, China. H1N1 virus was administered to the mice at $10 \mathrm{LD}_{50}$ intranasally.

\section{Experiment}

All the mice were separated into four different groups: normal group; infected group; toonaciliatin $\mathrm{K} 16.5$ and $33 \mathrm{mg} / \mathrm{kg}$, which received toonaciliatin $\mathrm{K} 16.5$ and $33 \mathrm{mg} / \mathrm{kg}$ intragastrically $1 \mathrm{~h}$ after exposure to the H1N1 virus and thereafter treated for the duration of 2 weeks. Infection was induced by exposing the anesthetized mice to the $\mathrm{H} 1 \mathrm{~N} 1$ virus $\left(10 \mathrm{LD}_{50}\right.$ in a volume of $\left.30 \mu \mathrm{l}\right)$ intranasally at day zero. At the end of the protocol, survival, body weight and clinical symptoms were observed in all mice.

\section{Isolation of lung and estimation of lung} index

All the animals were sacrificed by cervical dislocation and the lung was removed from each animal. The isolated lung was stored in $10 \%$ phosphate-buffered formalin. Weight of the isolated lung was estimated and lung edema was estimated by determining the lung index.

\section{Histopathology study}

The left lobe from the isolated lung was placed in liquid paraffin and a tissue section of $5 \mu \mathrm{m}$ thickness was sectioned by microtome. Further $\mathrm{H}+\mathrm{E}$ staining was used to stain the tissue and histopathological alteration was examined by using a trinocular microscope. Pathological score from the scale $0-3$ of lung tissue was calculated as per the previously reported study.

\section{Assessment of chemokines and cytokines}

Isolated lung tissue was homogenized and levels of chemokines (MIP-1 and MCP-1) and cytokines (INF- $\alpha$, TNF- $\alpha$, IL-1 and IL-6) were estimated in the tissue homogenate as per the instructions given by the manufacturer of the ELISA kits.

\section{Western blot assay}

Protein samples were isolated from homogenized tissues and quantified using a bicinchoninic acid (BCA) assay kit. We used $10 \%$ sodium dodecyl sulfate-polyacrylamide gel electrophoresis (SDSPAGE) to separate the proteins. Proteins were then transferred to a nitrocellulose membrane using an electroblotting technique. The membrane was blocked using a 5\% blocking solution (non-fat milk) and then incubated in a blocking buffer with the following primary antibodies overnight at $4^{\circ} \mathrm{C}$ : TLR-7 (1 : 1000; Santa Cruz Biotechnology, USA), NF-кB p65 (1 : 200; Santa Cruz Biotechnology, USA), MyD88 (1 : 1000; Santa Cruz Biotechnology, USA) and GAPDH (1 : 1000; Cell Signaling Technology, USA). The following day, goat secondary antibody conjugated with horseradish peroxidase (HRP) was added to the blocking buffer (1:1,000, non-fat milk), and a chemiluminescence kit (Thermo Fisher Scientific, Shanghai, China) was used to detect the proteins. Chemiluminescence was used to enhance the blot and ImageLab software was used to perform the densitometric analysis of blots.

\section{Reverse-transcription polymerase chain reaction (RT-PCR)}

RNA was isolated from separated lung tissue using TRIzol Reagent (Thermo Fisher). The RevertAid First Strand cDNA Synthesis Kit (Thermo 
Table I. Primer sequence used in the RT-PCR

\begin{tabular}{|lrr|}
\hline Primer & Forward & Reverse \\
\hline TLR7 & 5'-GGTGGCAAAATTGGAAGATCC-3' & 5'AGCTGTATGCTCTGGGAAAGGTT-3' \\
\hline MyD88 & 5'-CCAGAGTGGAAAGCAGTGTC-3' & 5'-GTCCTTCTTCATCGCCTTGT-3' \\
\hline NF-אB p65 & 5'-ATGTGCATCGGCAAGTGG-3' & 5'-CAGAAGTTGAGTTTCGGGTAG-3' \\
\hline iNOS & 5'-GTTCTCAAGGCACAGGTCTC-3' & 5'-GCAGGTCACTTATGTCACTTATC-3' \\
\hline GAPDH & 5'-ACCACCATGGAGAAGGCTGG-3' & 5'-CTCAGTGTAGCCCAGGATGC-3' \\
\hline
\end{tabular}

A

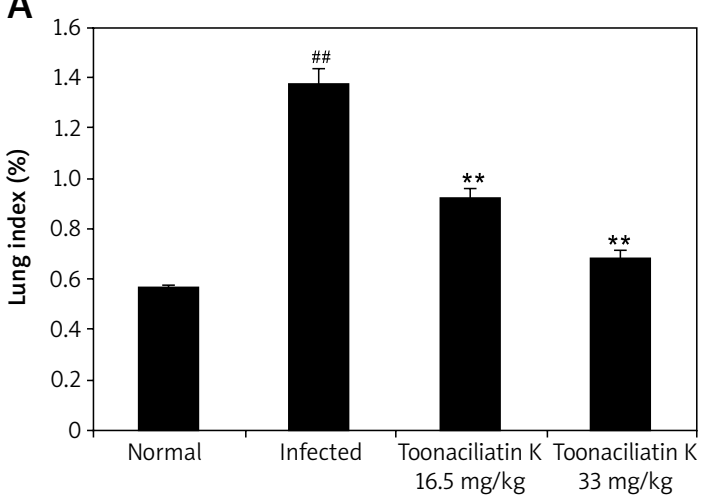

B

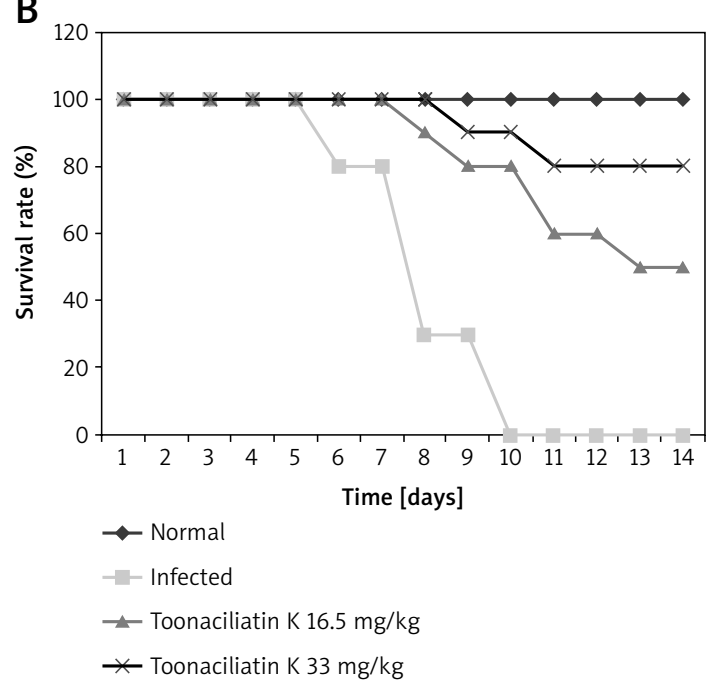

Figure 1. Toonaciliatin $\mathrm{K}$ improves the survival rate and lung index of H1N1 infected lung injured mice $(n=10)$ ${ }^{\# \#} P<0.01$ compared to normal group; ${ }^{* *} p<0.01$ compared to infected group of mice.

Fisher) was used to reverse-transcribe the RNA. Specific primers were mixed with RT-2 SYBR green master mix to evaluate gene expression by RT-PCR. The procedure used for all samples was as follows: $98^{\circ} \mathrm{C}$ for $2 \mathrm{~min}$, followed by $25-40 \mathrm{cy}$ cles of $98^{\circ} \mathrm{C}$ for $10 \mathrm{~s}$, then $55^{\circ} \mathrm{C}$ for $5 \mathrm{~S}$, and $72^{\circ} \mathrm{C}$ for $20 \mathrm{~s}$. mRNA expression levels of MyD88, TLR-7, iNOS, NF- $\kappa$ B p65 and GAPDH were calculated according to relative standard curves, which were generated by plotting the quantification cycle (Cq) against the log amount of total cDNA added to the reaction. The $2^{-\Delta \Delta C a}$ method was used to estimate the expression of the relative target gene (Table I).

\section{Statistical analysis}

All data were expressed as mean $\pm \operatorname{SEM}(n=10)$. The statistical analysis was performed using one way ANOVA. Post-hoc comparison of means was carried out by Dunnett's post hoc test (Version 6.1, GraphPad Prism Software, Inc., San Diego, CA, USA). The level of statistical significance was set at $p<0.05$

\section{Results}

\section{Effect of toonaciliatin $\mathrm{K}$ on the survival rate}

Assessment of the effect of toonaciliatin $\mathrm{K}$ treatment on the survival rate and lung index of H1N1 infected lung injured mice is shown in Figure 1. It was observed that the survival rate of $\mathrm{H} 1 \mathrm{~N} 1$ infected mice was reduced compared to the normal group of mice. However, the survival rate was improved in the toonaciliatin $\mathrm{K}$ treated group compared to the infected group of mice in a dose-dependent manner. The lung index was found to be higher in the infected group compared to the normal group of mice. Treatment with toonaciliatin $K$ alleviates the lung index in H1N1 infected lung injured mice.

\section{Effect of toonaciliatin $\mathrm{K}$ on the histopathology of lung tissue}

Assessment of histopathology of lung tissue of toonaciliatin $\mathrm{K}$ treated $\mathrm{H} 1 \mathrm{~N} 1$ infected mice was done at the end of the protocol and the pathological score is shown in Figures $2 \mathrm{~A}, \mathrm{~B}$. Transverse 


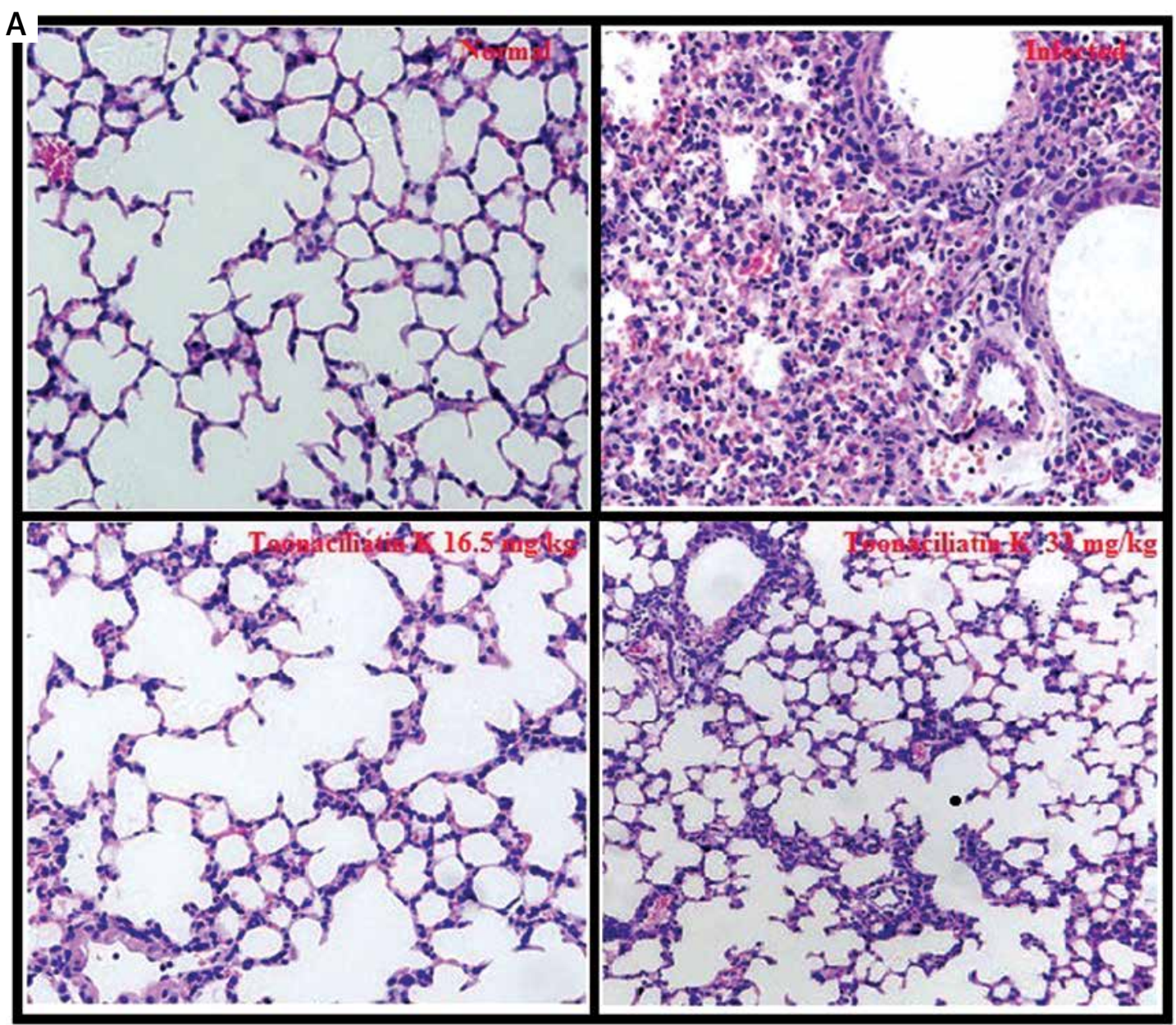

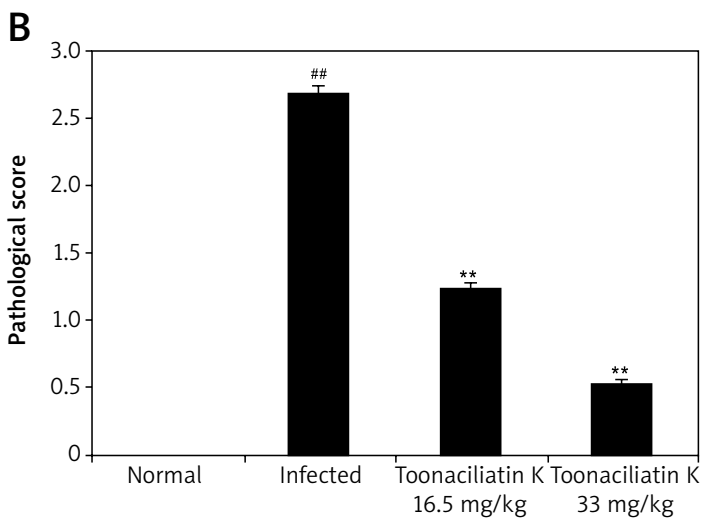

section (TS) of lung tissue of the infected group of mice show profuse hemorrhage, consolidation and edema too. However, histopathology of the toonaciliatin $\mathrm{K}$ treated group shows reduced edema, infiltration of neutrophils and thickness of the alveolar wall (Figure $2 \mathrm{~A}$ ). Moreover, the pathological score was higher in the infected group than the normal group of mice. Treatment with toonaciliatin $\mathrm{K}$ ameliorates the pathological score of lung tissue of H1N1 infected mice (Figure 2 B).
Figure 2. Toonaciliatin $\mathrm{K}$ attenuates the histopathology of lung tissue of H1N1 infected lung injured mice $(n=10)$. A - Histopathology of lung tissue, B - Pathological score

${ }^{\# \# P}<0.01$ compared to normal group; ${ }^{* *} p<0.01$ compared to infected group of mice.

Effect of toonaciliatin $\mathrm{K}$ on cytokines and chemokines

Levels of chemokines and cytokines in the lung tissue homogenate of toonaciliatin $\mathrm{K}$ treated $\mathrm{H} 1 \mathrm{~N} 1$ infected lung injured mice are shown in Figure 3. It was observed that the levels of cytokines (INF- $\alpha$, TNF- $\alpha, I L-1 \beta$ and IL- 6 ) and chemokines (MIP-1 and MCP-1) were significantly higher in the lung tissue homogenate of the infected group than the normal group of mice. There were lower levels of 
A

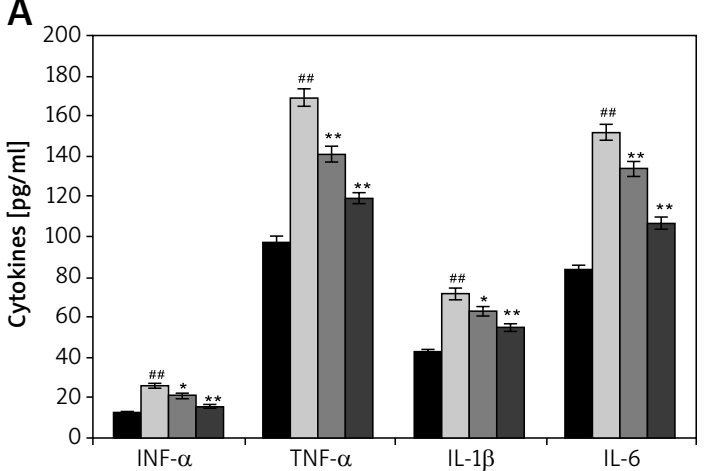

- Normal

$\square$ Infected

口 Toonaciliatin $\mathrm{K} 16.5 \mathrm{mg} / \mathrm{kg}$

- Toonaciliatin $\mathrm{K} 33 \mathrm{mg} / \mathrm{kg}$
B

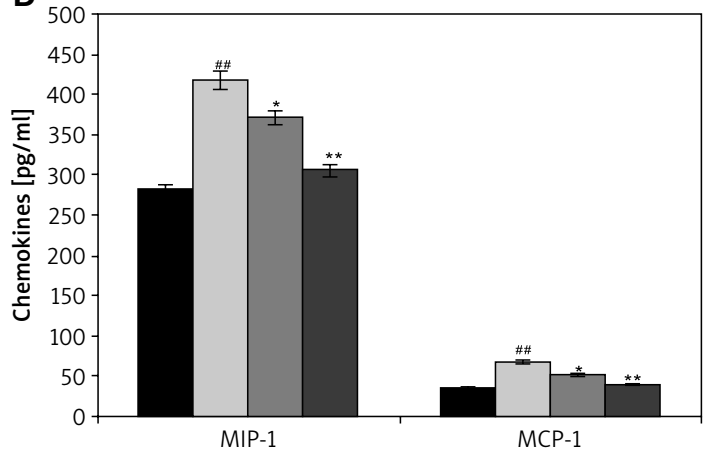

- Normal

$\square$ Infected

口 Toonaciliatin $\mathrm{K} 16.5 \mathrm{mg} / \mathrm{kg}$

- Toonaciliatin K $33 \mathrm{mg} / \mathrm{kg}$

Figure 3. Toonaciliatin $\mathrm{K}$ attenuates the level of cytokines and chemokines in the lung tissue homogenate of H1N1 infected lung injured mice $(n=10)$. A - Histopathology of lung tissue, B - pathological score

${ }^{\#} P<0.01$ compared to normal group; ${ }^{*} p<0.05,{ }^{* *} p<0.01$ compared to infected group of mice.

A

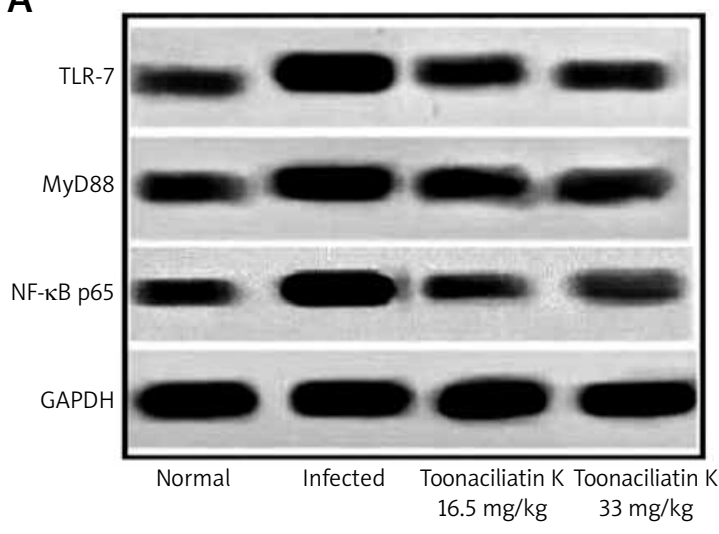

B

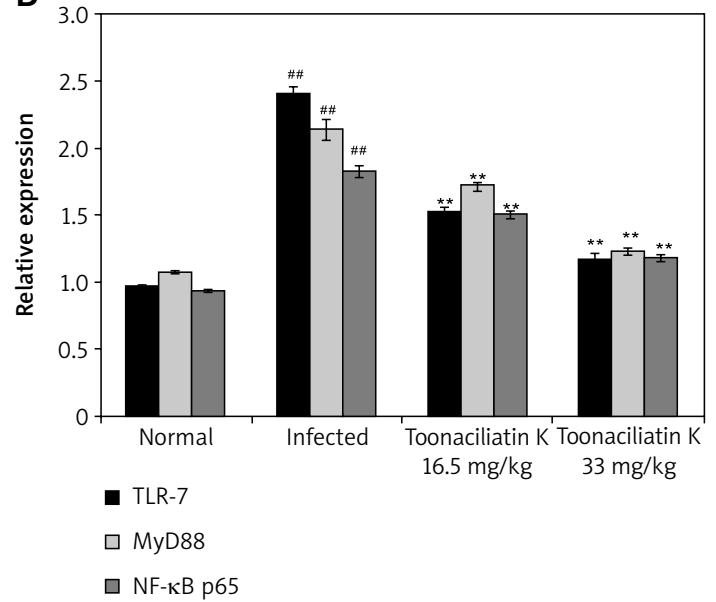

Figure 4. Toonaciliatin $\mathrm{K}$ attenuates the expression of NF- B p65, MyD88 and TLR-7 proteins in the lung tissue homogenate of $\mathrm{H} 1 \mathrm{~N} 1$ infected lung injured mice $(n=10)$

${ }^{\# \# P}<0.01$ compared to normal group; ${ }^{* *} p<0.01$ compared to infected group of mice.

chemokines and cytokines in the lung tissue in the toonaciliatin $\mathrm{K}$ treated group than the infected group of mice in a dose dependent manner.

\section{Effect of toonaciliatin $\mathrm{K}$ on expression of NF-kB p65, MyD88 and TLR-7}

Data of western blot assay showed the expression of NF-kB p65, MyD88 and TLR-7 proteins in the lung tissue homogenate of toonaciliatin $\mathrm{K}$ treated H1N1 infected lung injured mice (Figure 4). Expression of NF- $\mathrm{KB}$ p65, MyD88 and TLR-7 proteins was higher in the lung tissue homogenate of the infected group compared to the normal group of mice. There was lower expression of NF- $\mathrm{KB}$ p65, MyD88 and TLR-7 proteins in the lung tissue homogenate of the toonaciliatin $\mathrm{K}$ treated group compared to the infected group of mice.

\section{Effect of toonaciliatin $\mathrm{K}$ on mRNA expression of NF-KB p65, MyD88 and TLR-7}

The effect of toonaciliatin $\mathrm{K}$ on the mRNA expression of NF- $\kappa B$ p65, MyD88 and TLR-7 in the lung tissue homogenate of H1N1 infected lung injured mice is shown in Figure 5. There was higher mRNA expression of NF-KB p65, MyD88 and TLR-7 in the lung tissue homogenate of the infected group than the normal group of mice. Treatment with toonaciliatin $\mathrm{K}$ ameliorates the mRNA expression of NF- $\mathrm{KB}$ 


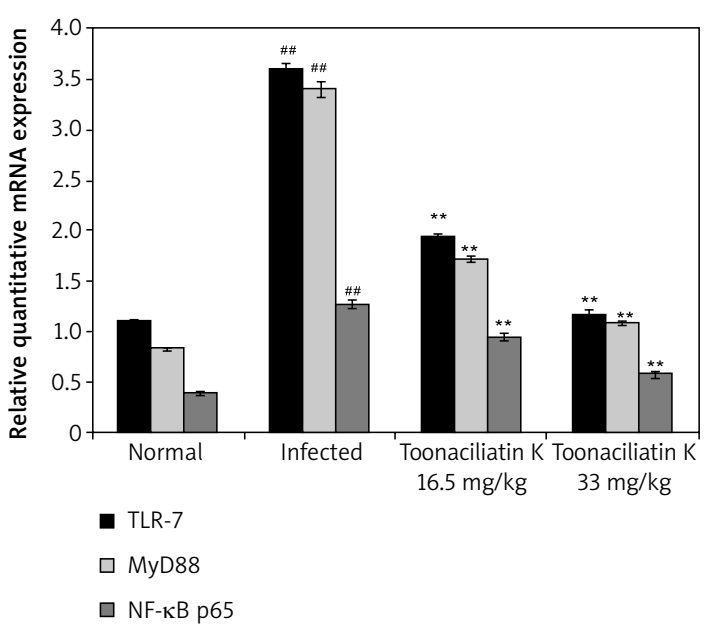

Figure 5. Toonaciliatin $\mathrm{K}$ attenuates the mRNA expression of NF- $\kappa B$ p65, MyD88 and TLR-7 in the lung tissue homogenate of H1N1 infected lung injured mice $(n=10)$

${ }^{\# \#} P<0.01$ compared to normal group; ${ }^{* *} p<0.01$ compared to infected group of mice.

p65, MyD88 and TLR-7 in the lung tissue homogenate of H1N1 infected lung injured mice.

\section{Discussion}

H1N1 virus induces lung infection which causes lung injury by altering the inflammation and immune cell infiltration in the lung [13]. Treatment of H1N1 infection with a conventional drug has several limitations and thus the present study determines the protective effect of toonaciliatin $\mathrm{K}$ on the H1N1 infected lung injured mice. The effect of toonaciliatin $\mathrm{K}$ was assessed by estimating the survival rate and lung edema by the lung index. Histopathological changes were determined by $\mathrm{H}+\mathrm{E}$ staining and western blot and an RT-PCR study was also performed on the lung tissue homogenate.

The H1N1 infection induced mouse model is well reported and also shows the inflammation of lung tissue and higher immune response [14]. CD8(+) Ts cells are involved in the chronic immune response in several diseases such as multiple sclerosis, systemic lupus erythematosus, and systemic sclerosis [15]. Thus this study also induces lung infection of H1N1 virus in a mouse model. H1N1 infection is associated with high mortality. Data of the study also suggested the lower survival rate in the infected group and treatment with toonaciliatin $\mathrm{K}$ enhances the survival rate in a dose dependent manner. Moreover, toonaciliatin K treatment attenuates lung edema by reducing the lung index compared to the infected group of mice. The literature reveals that H1N1 infection leads to enhancement of the concentration of cytokines due to an excessive immune response [16]. Chemokines are activated due to viral infection enhancing the infiltration of leukocytes in the lung. Further macrophages and phagocytes secreted inflammatory cytokines which causes lung injury $[17,18]$. Data of the investigation reveal that treatment with toonaciliatin $\mathrm{K}$ reduces the level of cytokines and chemokines in the lung tissue compared to the infected group of mice. Moreover, toonaciliatin $\mathrm{K}$ ameliorates the histopathological changes in the lung tissue of H1N1 infected lung injured mice.

TLR-7 is a receptor of the TLR family which recognizes the single-stranded RNA (ssRNA) of the virus and which further leads to enhancement of macrophages and cytokines in the lung tissue by activating the MyD88 dependent pathway which further activates NF- $\kappa B$ p65 [19]. Activation of NF- $\mathrm{B}$ p 65 enhances the inflammation and immune response by regulating the secretion of chemokines, interferon, cytokines and growth factors [20]. Inflammation in the lung tissue reduces the function of the lung, which leads to an increase in mortality [21, 22]. Results of the investigation reveal that the expression of TLR-7, Myd88 and NF- $\kappa B$ p65 was reduced in the lung tissue of the toonaciliatin $\mathrm{K}$ treated group compared to the infected group of mice.

In conclusion, data of the study suggested that toonaciliatin $\mathrm{K}$ protects against lung injury in lung H1N1 lung infection. Toonaciliatin K modulates immune cell function and inflammatory cytokines by regulating the TLR-7/Myd88/NF- $\kappa B$ p65 pathway in $\mathrm{H} 1 \mathrm{~N} 1$ induced lung injured mice.

\section{Acknowledgments}

All the authors of this manuscript are thankful to Tongliao City Hospital, for providing the necessary facility for the presented work.

\section{Conflict of interest}

The authors declare no conflict of interest.

\section{References}

1. Maeda N, Uede T. Swine-origin influenza-virus-induced acute lung injury: novel or classical pathogenesis? World J Biol Chem 2010; 1: 85-94.

2. Mancuso P, Lewis C, Serezani CH, Goel D, Peters-Golden M. Intrapulmonary administration of leukotriene B4 enhances pulmonary host defense against pneumococcal pneumonia. Infect Immun 2010; 78: 2264-71.

3. Guo L, Wang YC, Mei JJ, et al. Pulmonary immune cells and inflammatory cytokine dysregulation are associated with mortality of IL-1R1 ${ }^{-/}$mice infected with influenza virus (H1N1). Zool Res 2017; 38: 146-54.

4. Okur M, Erbey F, Yazicioglu O, et al. H1N1 influenza A virus related pneumonia and respiratory failure. Indian J Virol 2013; 24: 85-9.

5. Majewska M, Szczepanik M. The role of Toll-like receptors (TLR) in innate and adaptive immune responses and 
their function in immune response regulation. Postep Hig Med Dosw (Online) 2006; 60: 52-63.

6. Lester SN, Li K. Toll-like receptors in antiviral innate immunity. J Mol Biol 2013; 426: 1246-64.

7. Roy A, Saraf S. Limonoids: overview of significant bioactive triterpenes distributed in plants kingdom. Biol Pharm Bull 2006; 29: 191-201.

8. Kim J, Jayaprakasha GK, Patil BS, Limonoids and their anti-proliferative and anti-aromatase properties in human breast cancer cells. Food Function 2013; 4: 258-61.

9. Zunino SJ, Storms DH, Freytag TL et al. Dietary supplementation with purified citrus limonin glucoside does not alter ex vivo functions of circulating $T$ lymphocytes or monocytes in overweight/obese human adults. Nutr Res 2016; 36: 24-30.

10. Akihisa T, Takahashi A, Kikuchi T et al. The melanogenesis-inhibitory, anti-inflammatory, and chemopreventive effects of limonoids in $n$-hexane extract of azadirachta indica a. juss. (neem) seeds. J Oleo Sci 2011; 60: 53-9.

11. Mahmoud MF, Hamdan DI, Wink M, El-Shazly AM. Hepatoprotective effect of limonin, a natural limonoid from the seed of Citrus aurantium var. bigaradia, on D-galactosamine-induced liver injury in rats. Naunyn Schmiedeberg's Arch Pharmacol 2014; 387: 251-61.

12. Gou HX, Ye J, Wang YR, et al. The anti-inflammatory activity of toonaciliatin $\mathrm{K}$ against adjuvant arthritis. BioMed Res Int 2017; 2017: 9436280.

13. Jia X, Liu B, Bao L, et al. Delayed oseltamivir plus sirolimus treatment attenuates H1N1 virus-induced severe lung injury correlated with repressed NLRP3 inflammasome activation and inflammatory cell infiltration. PLoS Pathog 2018; 14: e1007428.

14. Price I, Mochan-Keef ED, Swigon D, et al. The inflammatory response to influenza A virus (H1N1): an experimental and mathematical study. J Theor Biol 2015; 374: 83-93.

15. Filaci G, Rizzi $M$, Setti $M$, et al. Non-antigen-specific CD8(+) T suppressor lymphocytes in diseases characterized by chronic immune responses and inflammation. Ann N Y Acad Sci 2005; 1050: 115-23.

16. Oslund KL, Baumgarth N. Influenza-induced innate immunity: regulators of viral replication, respiratory tract pathology and adaptive immunity. Future Virol 2011; 6: 951-62.

17. Moldoveanu B, Otmishi P, Jani P, et al. Inflammatory mechanisms in the lung. J Inflamm Res 2008; 2: 1-11.

18. Huang R, Zhong T, Wu H. Quercetin protects against lipopolysaccharide-induced acute lung injury in rats through suppression of inflammation and oxidative stress. Arch Med Sci 2015; 11: 427-32.

19. Hopkins PA, Sriskandan S. Mammalian Toll-like receptors: to immunity and beyond. Clin Exp Immunol 2005; 140: 395-407.

20. Liu T, Zhang L, Joo D, Sun SC. NF-kappaB signaling in inflammation. Signal Transduct Target Ther 2017; 2: 17023.

21. Hancox RJ, Poulton R, Greene JM, et al. Systemic inflammation and lung function in young adults. Thorax 2007; 62: 1064-8.

22. Cao Q, Li B, Wang X, Sun K, Guo Y. Therapeutic inhibition of CXC chemokine receptor 2 by SB225002 attenuates LPS-induced acute lung injury in mice. Arch Med Sci 2017; 14: 635-44. 